\title{
Socio-economic, Demographic and Environmental Relationship of Maijchar Region Bangladesh for Application in Participatory GIS
}

\author{
Sultana Nasrin Baby ${ }^{1 *}$, Nahlah Abbas ${ }^{2}$ and Hugh Kirkman ${ }^{3}$ \\ ${ }^{1}$ RMIT University, 124 La Trobe St, Melbourne, VIC (30 00), Australia \\ ${ }^{2}$ School of Engineering and Technology, Central Queensland, University, Melbourne (30 00), Australia \\ ${ }^{3} 5 \mathrm{a}$ Garden Grove, Seaholme, VIC (30 18), Australia
}

\section{Corresponding Author}

Sultana Nasrin Baby

e-mail: snb.sdml@gmail.com

\section{Article History}

Article ID: AR1878

Received in $06^{\text {th }}$ June, 2018

Received in revised form $19^{\text {th }}$ August, 2018

Accepted in final form $20^{\text {th }}$ August, 2018

\begin{abstract}
Comprehensive and accurate maps appropriate for decision making at the local level are outmoded or presently not available in the Maichar Union local community, Bangladesh. This paper aims at understanding the use and the consequences of Participatory Geographic Information System (PGIS) in this local community and presents a community map based on Participatory Rural Appraisal (PRA) and Geographic Information System (GIS) practices (particularly photo mapping). It links to advanced spatial analysis in socio-economic, demographic, and environmental-correlation. PRAGIS was applied and examined to identify its likelihood to help local communities of the Maichar Union in the management of their socio-economic, demographic, and environmental condition. Involvement of the local community in identifying their information needs. Gathering data and natural resources information was greatly valuable in combination with GIS. During the assessment of PRAGIS, it was recognized that for developing plans the emphasis should be basically on the primary stakeholder, such as the local community and the poor rather than on technical experts. This rarely takes place at the ground level and could be a restrictive factor for the efficiency of GIS as a participatory tool although it facilitates participating diverse stakeholders to make an appropriate decision by engaging all relevant stakeholders to participate. This study shows that in a developmental context PRAGIS should be viewed primarily as a consultative, participatory methodology rather than a predominantly technological aid. The outcomes of this research have made a major contribution in developing the Maichar Union local community particularly for sanitation and education sectors.
\end{abstract}

Keywords: Bangladesh, participatory GIS, socio-economic, demographic, environmental relationship

\section{Introduction}

Participation is now broadly encouraged and recognized as a philosophy and approach in development but the vast gap continues to exist between fashionable rhetoric and field reality (Carver, 2003). Among a great number of participation types, the Participatory Rural Appraisal (PRA) approach is one of the most effective that has emerged, grown and spread in the early 1990s (Koralagama et al., 2007). PRA is defined as a developing group of methods and approaches to enable local people (rural or urban) to express, improve, share and analyze their knowledge of life and conditions, to plan and to perform (McCall and Dunn, 2012). It is optimized by a bottomup approach, well-defined objectives, feasible solutions, and remedies (Ricaurte, 2014). PRAs appear as a popular approach in community development planning practised in over 130 countries to collect data on health, education, natural resource usage, infrastructure, and the environment (Sieber, 2006). PRA techniques are cost-effective approaches; they utilize locally available resources, can produce information rapidly, and optimize a sense of belonging by communities (Kalibo and Medley, 2007). The most developed and tested approach of PRA is participatory mapping and modelling using geographic information systems (GIS) (King, 2002).

Participatory GIS (PGIS) is the integration of PRA methods and (GIS). PGIS has now become a common form of mapping that enables local people to generate their own maps and models and using them for their own research and analysis (Baldwin et al., 2013). PGIS has been successfully used in natural resources management (soil and water conservation, forestry, fisheries, wildlife, village planning, agriculture, health, nutrition, food security and programs for the poor) especially in developing countries including Bangladesh, Bolivia, Botswana, Brazil, Burkina Faso, Cambodia, Cameroon, Chile, Colombia, Costa Rica, Ecuador, Egypt, Ethiopia, the Gambia, Ghana (Gautam et al., 2002; King, 2002; Tripathi and Bhattarya, 2004; McCall and Minang, 2005; Chambers, 2006; Dunn, 2007; Gomez et al., 2015). 
Bangladesh is a populous developing country mainly based on agriculture (Hassan and Nhemachena, 2008). Its population is $80 \%$ rural and relies basically on agriculture. Twenty-fivepercent of the rural population live under the poverty line and lack education institutes, health clinics, basic infrastructures such as adequate roads and sewers (Rasul and Thapa, 2004). In addition, rural natural resources such as timber harvesting, honey collection and aquaculture are being overexploited for commercial purposes due to mismanagement (Alam et al., 2009). Poverty and mismanagement coupled with natural hazards such as floods lead to a prolonged socio-economic and environmental disturbances. These indicate the need for well-planned strategic systems such as APRGIS in a country like Bangladesh.

Unions are the smallest rural administrative and local government units in Bangladesh. Each Union is made up of nine Wards. Usually, one village is designated as a ward. There are 4,554 unions in Bangladesh. A Union Council consists of a chairman and twelve members including three members exclusively reserved for women. Union Parishads are formed under the Local Government (Union Parishads) Act, 2009. The boundary of each Union is demarcated by the Deputy Commissioner of the District. A Union Council is the body primarily responsible for agricultural, industrial and community development within the local limits of the union (Islam et al., 2016).

Machar Union in Bangladesh was selected as a case study area to digitize PRA generated social/resource data in a large-scale map where individually enrolled households are identified by location and bring the capacity building to the development managers and planners so that efficiency and accuracy in future planning processes are enabled by implementation of GIS technology. This leads to support maintaining ecological balance and overall sustainable development through protection and improvement of the environment, and to assemble a mapping tool suitable for showing all stakeholders.

\section{Materials and Methods}

The present experiment was carried out to study the effect of socio-economic, demographic and environmental relationship of Maijchar region Bangladesh for application in participatory GIS. Maijchar is one of the 11 unions (the lowest level of local government) of Bajitpur Upazila, located at latitude $24^{\circ} 10^{\prime}$ $57 \mathrm{~N}$ and longitude $90^{\circ} 58^{\prime}$ 54E (Figure 1). Maijchar union holds 24 villages (each village holds 100 to 200 households) covering a total area of $22 \mathrm{~km}^{2}$. There are a total of 3173 households in the union with a population of 16,619. Maijchar union lies in a wetland area and is surrounded by two big rivers the Meghna River in the east and the Ghoraute River in the west (Figure 1). The villages are surrounded by wetland and the only communication between the villages during the monsoon is by boat. Village livelihoods are predominantly from agriculture and fishing. Average maximum temperature $33.3^{\circ} \mathrm{C}$ and minimum temperature $12^{\circ} \mathrm{C}$; annual rainfall 2174

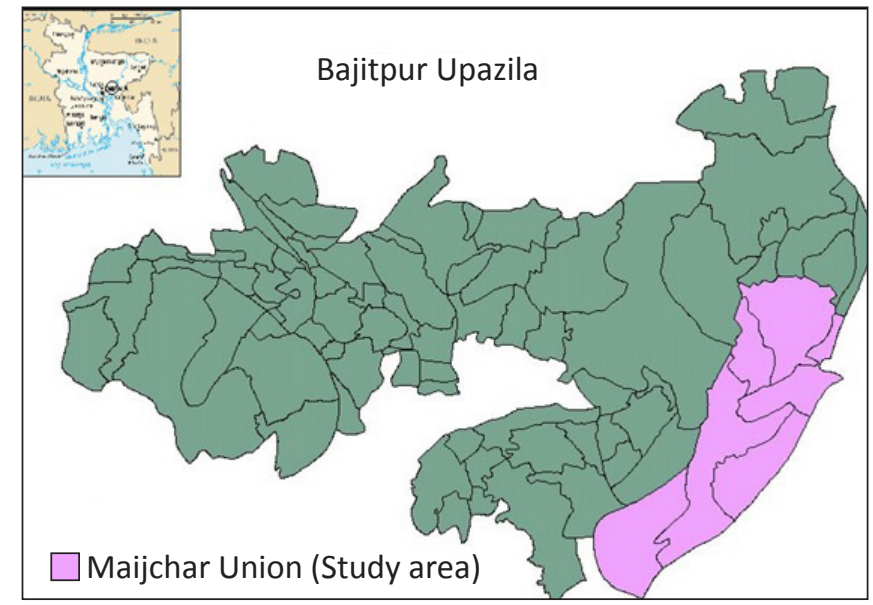

Figure 1: Map of study area

$\mathrm{mm}$. The northern part is hilly while the southern parts have depressions. The methodology applied is outlined in Figure 2. GPS survey generated a map showing the boundaries of the 24 villages. The map was then sent to the local community to mark each household's locations. The houses and main features of the villages, such as roads, schools, and clinics, were digitized by the researcher to produce the base map and send it to the local community for extensive PRA. The database captured from the PRA was imported and linked

GIS survey of all the village
$\begin{gathered}\text { Produce hard copy maps of } \\ \text { the with boundaries of the } \\ \text { villages }\end{gathered}$

Send the hard copies to the communication people

Put the household location on those maps by the communication ppeople

Put the household location on those maps by the communication people

Digitize the location of those thous holds in the base map $\checkmark$ locations of all the households and imortant physical features $\downarrow$

Enter the data capture during extensive PRA and link the database with indivisual households of the base map

Figure 2: Data process flow chart
Produce hard copies of the maps and send to the end users

Analyze hard copies of the maps and send to the end users

Produce maps showing different socio-economics aspects 
with features on the base map. The base map was analyzed based on public requirements. Ultimately a map showing the different socioeconomic features was produced.

The participatory GIS sessions in Maijchar union started in 2006 when the community agreed to a request to take part by drawing paper maps of their villages showing the location and family name of every household. They also marked the important physical features, like schools, tube-wells, sanitary latrines, mosques and temples. A wellbeing ranking of the villagers was also completed on these maps, called social and resource maps which were available for adoption as a tool by which to plan the development activities in the community that prepared extract valuable allocation of land resource and access to. However, such maps had to be handled with care in order to avoid damage. Also, it was not always possible to show socioeconomic data like well-being ranking on the maps and in many cases, maps were little better than village mapped.

\section{Results and Discussion}

Participatory techniques have been the primary tool for obtaining community and resource information (Tripathi and Bhattarya, 2004). This process empowers the villagers and local communities to manage their own resources more efficiently (Reed, 2008). On the other hand, in data collection of the quantitative information needed to upgrade for planning, and monitoring of activities disagreed to enhance economic development (Tripathi and Bhattarya, 2004). It seems that traditionally qualitative and quantitative data collection analysis and management have been done separately (Bryman, 2006). This may be due to the reference of disciplines: social scientists have continued to conduct the participatory information gathering and analysis, while colleagues from the natural sciences and IT have been able to collect and manage the quantitative information. The data can be geo coded and this is a scope for using GIS for importing data integration. At District or National level, maps are often made conducting an analysis of socio-economic environment indicators, commonly called 'indicators of development", these Indicators are used for policy planning to identify both development priorities and geographic regions of activity (Islam, 2016). However, the development in GIS can lead to the disempowerment of local people all but preclude them from participation in decision making because of the planning process from the people affected that can be engaged. What information would be useful to the community together for economic development? What information can a GIS provide? Lack of discussion with the community regarding spatial information that would be useful to them developing their participation in planning conforming to economic development policy may promote frailer of plans to community ownership of the new approaches. GIS information as not meant for them but other for the policy makers, planners and researchers to use closely, there is scope to test and sampling the opposite prevention: GIS as an enabling tool for all stakeholders. However, if community needs have not been identified well enough for the data delivery to be assembled, top-down development paradigm will continue to be actively encouraged (Pandian et al., 2018).

Participatory GIS can produce maps and include representation of the social and temporal components. That has been identified as relevant via community consultation. Thus one screen digitizing of feature interpreted management GIS lab displays of verified satellite images can be covering to a data dictionary developed clearing field work. Informal maps meet local needs, while technical maps tend to be used in contact with external agencies. In both cases, however, it is best of maps are based upon traditional ecological and cultural knowledge and practice. Global Positioning System (GPS) technology is being used to geocoded local data in order to bridge the gap between these two kinds of maps (Haklay, 2008). Once local information is geocoded, it can be exchanged with similarly geocoded global databases and satellite sensing systems which are evolving to offer enough detail to be useful in addressing local problems worldwide (Haklay, 2008).

The purpose of this thorough participatory GIS was to allow the community to review and locate their resources with confidence, identify and prioritize their problems, set action plans to solve their problems and to monitor the progress of their work. The intention of the entire participatory GIS integration was to increase the participation of all concerned and to develop a planning tool that is visual and very easy to understand, even by illiterate persons. This kind of initiative had previously been undertaken in Nepal and the aim was to replicate it in Bajitpur. Help was sought from experts on the issue, and an exposure visit to Nepal was arranged involving community people, [Mymensingh staff and the GIS unit of CARE Bangladesh].

The village boundaries were identified by community members' geo-referenced using GPS survey (Figure 3). The household locations were established during the same survey, using the stakeholder's maps as a guide. The nature of the data directory can be dewed for the data summary.

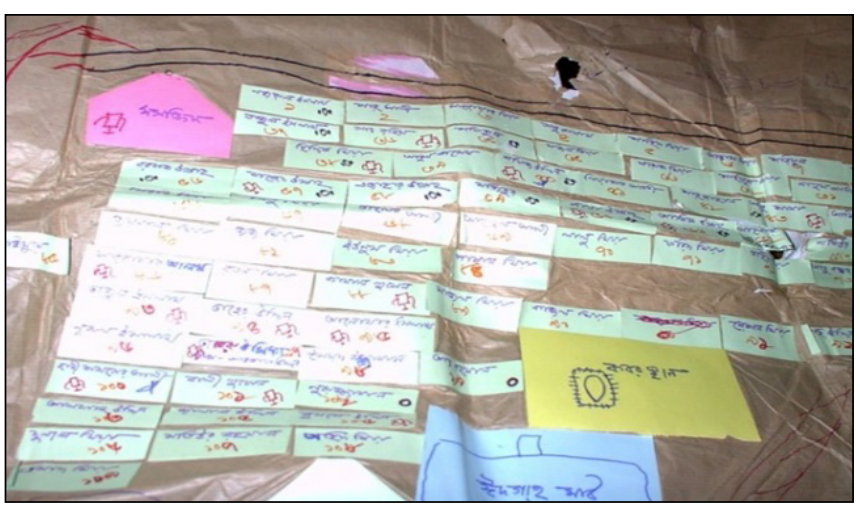

Figure 3: Administrative boundaries in Maijchar union created by the local community 
Table 1 comprises the detailed data about Maijchar union Participatory GIS can produce maps and include representation of the social and temporal components (Akhbari, 2010, Das and Tripathi, 2012). That has been identified as relevant via community consultation. Thus one screen digitizing of feature interpreted management GIS lab displays of verified satellite images can be covering to a data dictionary developed clearing field work. Informal maps meet local needs, while technical maps tend to be used in contact with external agencies. In both cases, however, it is best of maps are based upon traditional ecological and cultural knowledge and practice (Das and Tripathi, 2011). Global Positioning System (GPS) technology is being used to geocoded local data in order to bridge the gap between these two kinds of maps (Haklay, 2008). Once local information is geocoded, it can be exchanged with similarly geocoded global databases and satellite sensing systems which are evolving to offer enough detail to be useful in addressing local problems worldwide (Haklay, 2008).

\begin{tabular}{ll}
\hline Table 1: Basic data of Maijchar union \\
\hline Name of sub-district & Bajitpur \\
\hline Name of union & Maijchar \\
Agro-ecological zone & Sylhet wetland basin \\
Geographic region & North East region \\
Water region & Wetland floodplain region \\
Fisheries region & Inland open water capture fisheries \\
Type of local water & River, depression, lake, and \\
bodies & floodplain \\
Total village area & 26 km \\
Total house hold & 3173 \\
Total school & 20 \\
Total tub-well & 494 \\
Total sanitation latrine & 47 \\
Total population & 13,000 \\
\hline
\end{tabular}

The purpose of this thorough participatory GIS was to allow the community to review and locate their resources with confidence, identify and prioritize their problems, set action plans to solve their problems and to monitor the progress of their work. The intention of the entire participatory GIS integration was to increase the participation of all concerned and to develop a planning tool that is visual and very easy to understand, even by illiterate persons. This kind of initiative had previously been undertaken in Nepal and the aim was to replicate it in Bajitpur. Help was sought from experts on the issue, and an exposure visit to Nepal was arranged involving community people, [Mymensingh staff and the GIS unit of CARE Bangladesh].

The village boundaries were identified by community members' geo-referenced using GPS survey (Figure 3 ). The household locations were established during the same survey, using the stakeholder's maps as a guide. The nature of the data directory can be dewed for the data summary. Table 1 comprises the detailed data about Maijchar union

The second outcome of Participatory GIS was the identification of sanitation which was one of the major problems to be addressed immediately. Maijchar villagers used to defecate in the open. It was almost impossible for people to pass along the village roads during the wet seasons without enduring the noxious odour of human excreta (Figure 4). In addition, accessing to tube well water was very rare (Figure 5). This led to hygiene-related diseases such as diarrhea and intestinal diseases. Villagers agreed to eradicate the problem as soon as possible by their self-initiatives. Thus a $100 \%$ sanitation program was undertaken for Maijchar union. Monitoring of progress was community-based (Figure 6).

Maijhchar Shampur village is one of 24 villages selected to

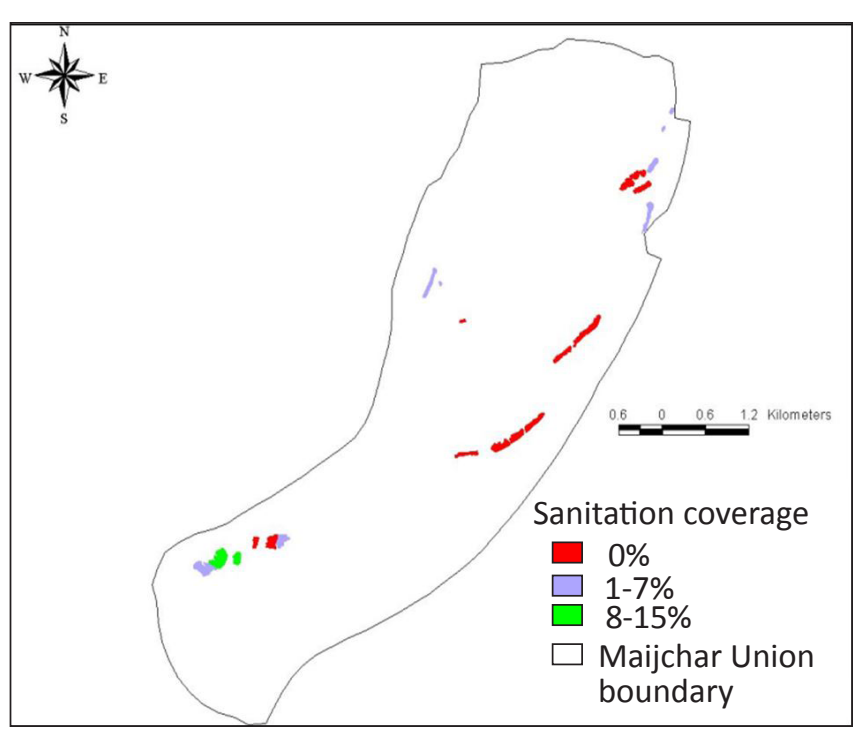

Figure 4: Baseline map sanitation status, where red blue and green represents no sanitation, $1-7 \%$ sanitation and $5-18 \%$ sanitation, respectively

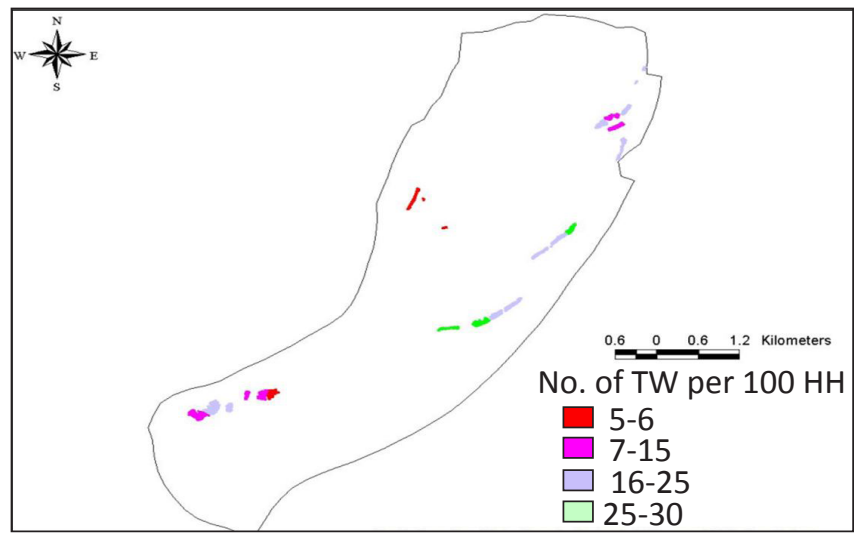

Figure 5: Baseline map of tubewell water supply where red, purple, blue and green represent 

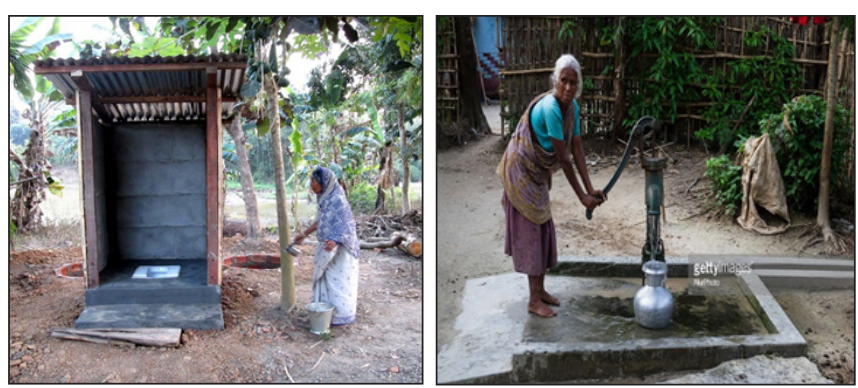

Figure 6: Shows the sanitation (left) and tubewell water supply (right)

show the spread of hygiene-related disease from when the study commenced to when it ended. (Figure 7 and 8).This village is also divided into two segments- one larger (West Part) and another one is smaller (East Part). The population density of the South-West side of both village parts is more than other parts.

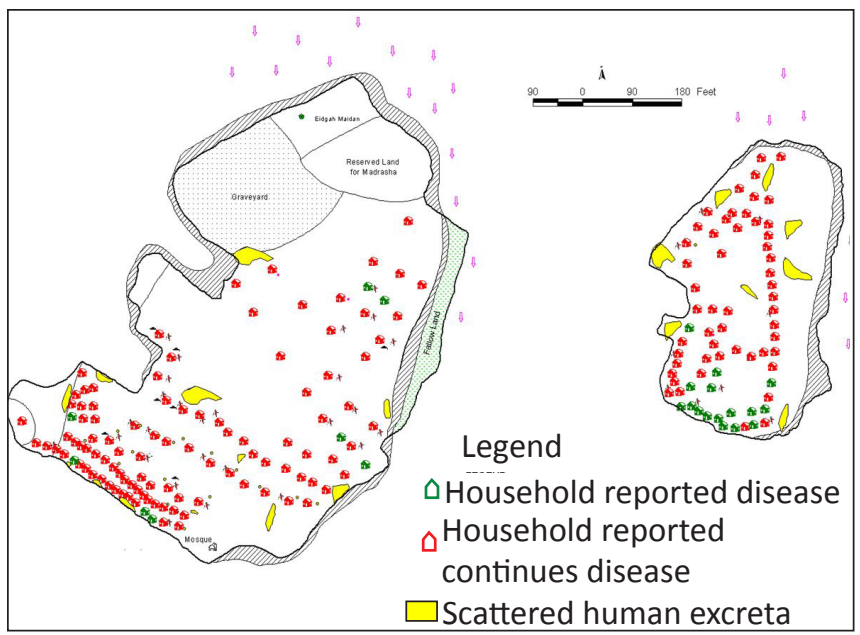

Figure 7: statuses of Hygiene related diseases before Maijhchar Shampur sanitation program

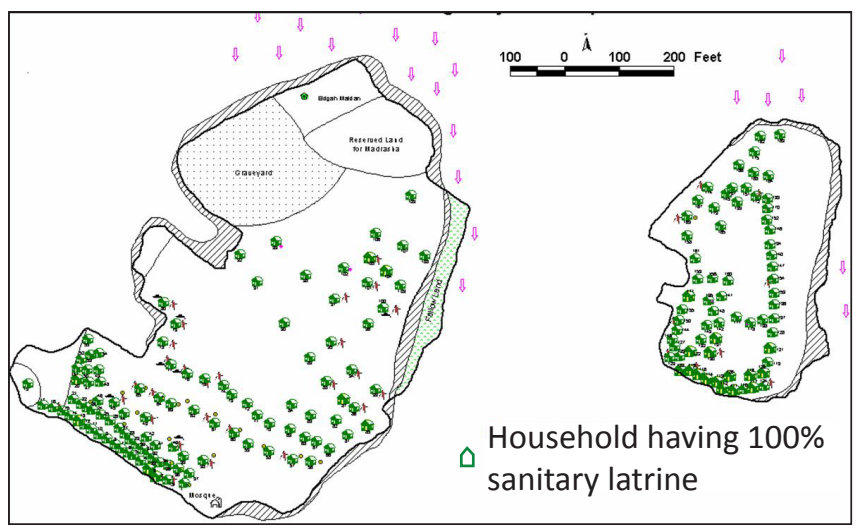

Figure 8: Sanitation status of MaijhcharShampurvillage after program implementation

Participatory GIS was also used to identify the number of schools in each village. For example, Figure 9 shows the villages with and without schools. It can be seen that the number of

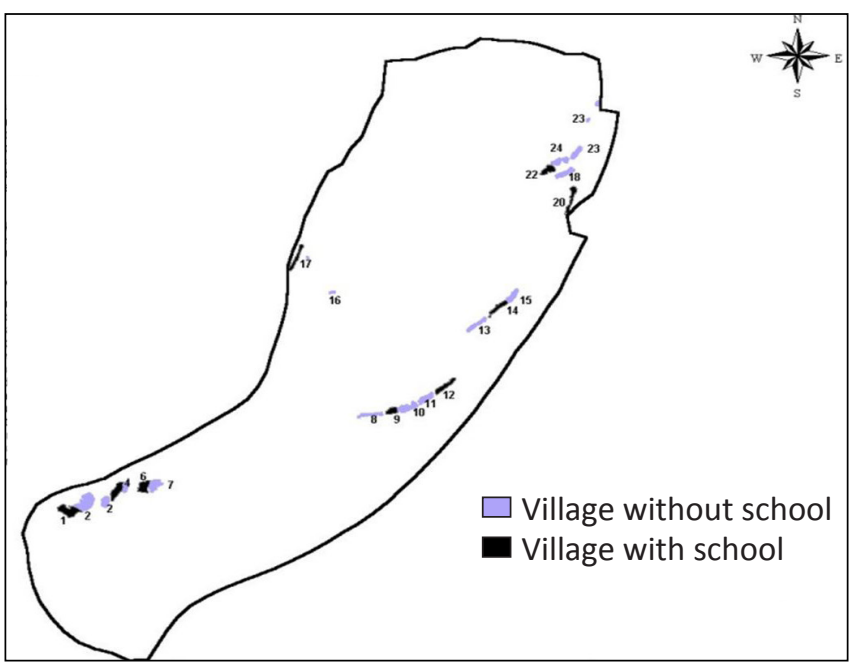

Para 1: Maijchar Shanmpur Daksin para

Para 5: Maijchar Maddahpara

Para 6: Maijchar Kazipara paschim Ati

Para 9: Baherbali paschim

Para 12: Baherbali purba

Para 14: Purakanda Maddah

Para 16: Shibpur

Para 17: Boali

Para 20: Ainerghop Dakhinpara

Para 22: Parkachua paschim para

Para 23: Parkachua purbapara Uttar Ati

Villages without school (13)

Para 2: Maijichar Shampur

Para 3: Maijichar Paschim para

Para 4: Maijichar Purba para

Para 7: Maijichar Kazipara Purba Ati

Para 8: Baherbali Naya Ati

Para 10: Baherbali Konabari

Para 11: Baherbali Maddahpara

Para 13: Purakanda Paschim

Para 15: Purakanda Purba

Para 18: Ainerghop pantharia Ati

Para 19: Ainerghop Muns Shantipur Ati

Para 21: Parkachua Sharifpur Gangoli

Para 21: Parkachua Purbapara Daksin Ati

Figure 9: Villages with and without schools in Mijchar Union

villages without schools is higher than those with a school. The result could draw the policy maker's attention to make more effort to improve the education status for the villagers and their children (Figure 10 and 11).

From the occupation and well-being map (Figure 12) it can see that most of the villagers have agriculture as their occupation. $\mathrm{X} \%$ of villagers is small entrepreneurs. The average economic condition of the villagers is not good and most of them belong to middle, poor and very poor category there are few exception. There are a few service holders in the village who all are poor to very poor.

It is possible in GIS to establish a hot link between objects of the map and an image, for instance a photograph.Then if we want to know the latrine type being used by a particular house owner, we can simply click that object which was previously linked with the real photograph of that household. 


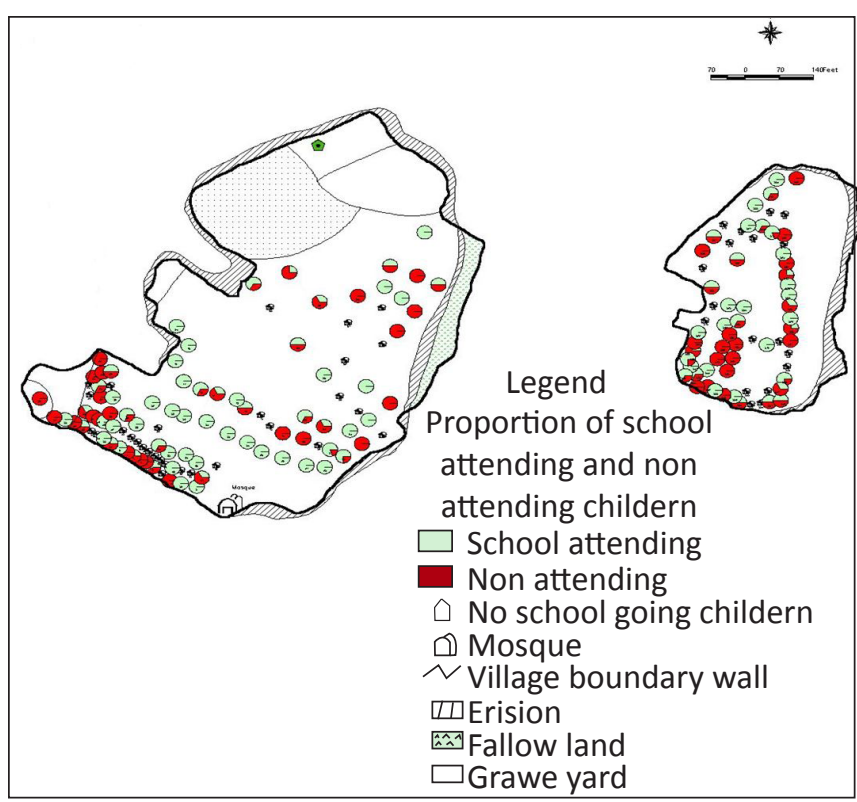

Figure 10: School aged children going and not going to school in Maijhchar Shampur villages

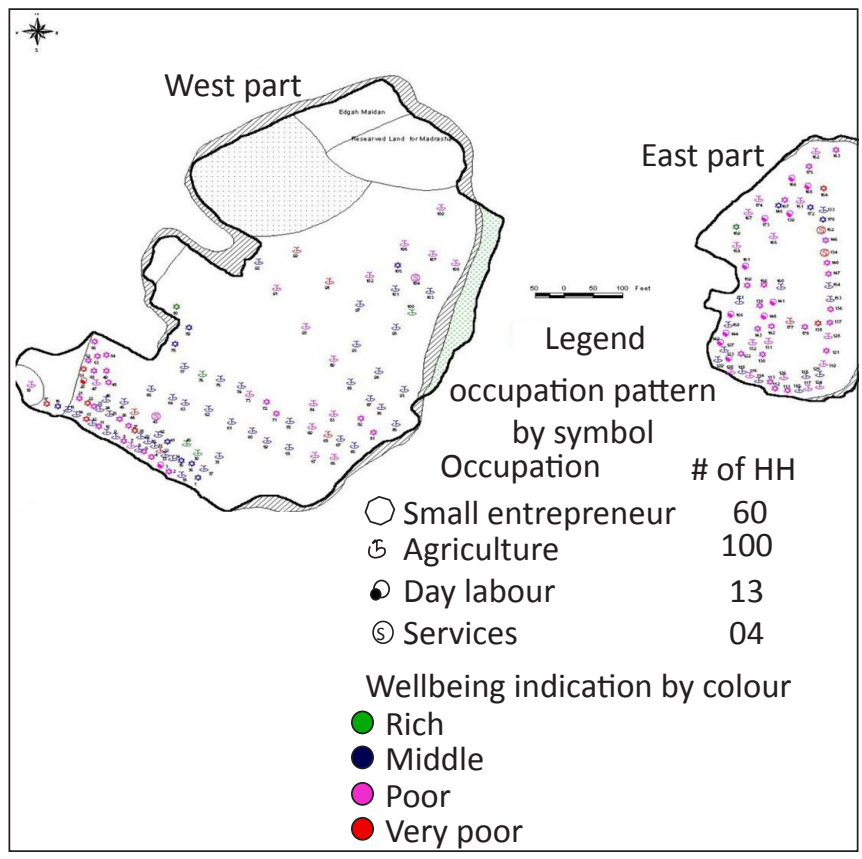

Figure 11: Occupation and wellbeing status of Maijchar Shampur

Figure 13. Demonstrates such kind of hot links.

\subsection{Risk assessment}

Major Problems as identified by application of GIS, found among the 24 village communities surveyed are mound The GIS team may not be provided with the updated information about changes. erosion by wave/river, open latrine/defecation, lack of safe water, Lack of health facility/Treatment, lack of education facility, communication (Boat/Road), malnutrition, dowry, villages are needed to pay dowry affected in wealth

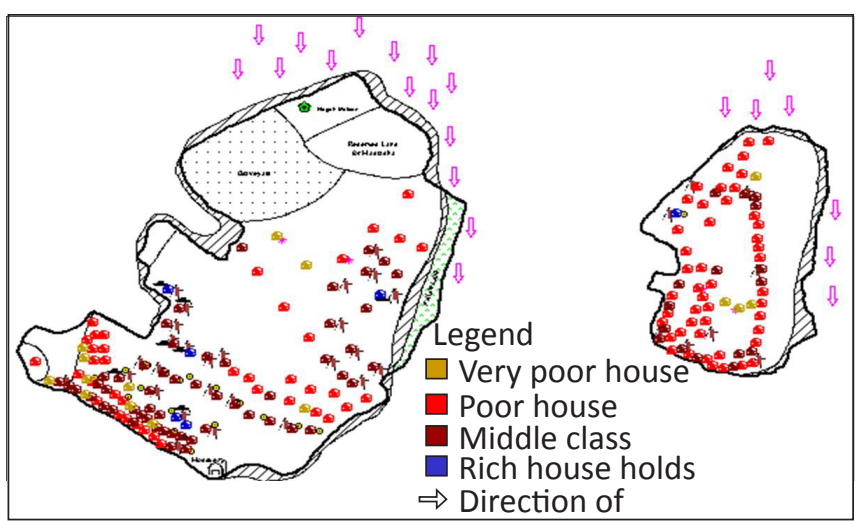

Figure 12: Base Map of MaijhcharShampur village with wellbeing analysis

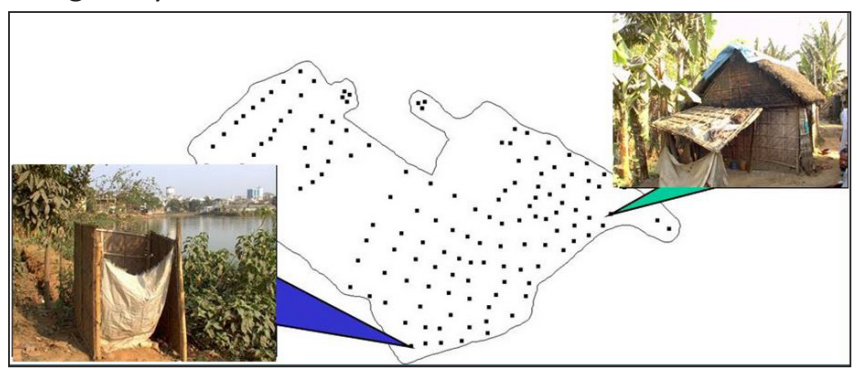

Figure 13: Demonstrates such kind of hot links

distribution, lack of opportunity for vegetable gardening, problem of Graveyard integrity, lack of fishing opportunity, early Marriage tradition, less support from Union Parishad, high unemployment rates and lack of Bazar/market Facility

Difficulties in application of GIS

There are various limitations to the use of GIS as outlined below.

- The shortage of skilled people will probably be the greatest obstacle in GIS use, Professional development of staff via GIS training is an essential requirement of over exploration of extant GIS staff capacity is to be overloaded.

- Lack of understanding other part of senior management could be a very critical obstacle.

- Some opportunity may be calculate of leaders do not want to above proven by implement in information access and transparency.

\section{Conclusion}

PRAGIS was applied to identify its likelihood to assist local communities of the Maichar Union in the management of their socio-economic, demographic, and environmental condition. Involvement of the local community in identifying their information needs. Gathering data and natural resources information was greatly valuable in combination with GIS. During the assessment of PRAGIS, it was recognized that for developing plans the emphasis should be basically on the primary stakeholder, such as the local community and the poor rather than on technical experts. 


\section{References}

Akhbari, M., 2010. Land use and Geographical Planning towards National Solidarity. International Journal of Bio-resource and Stress Management 1(3), 174-175.

Alam, G.M., Hoque, K., EKhalifa, M.T.B., Siraj, S.B., Ghani, M.F.B.A., 2009. The role of agriculture education and training on agriculture economics and national development of Bangladesh. African Journal of Agricultural Research 4(12), 1334-1350.

Baldwin, K., Mahon, R., McConney, P., 2013. Participatory GIS for strengthening transboundary marine governance in SIDS. In Natural Resources Forum 37(4), 257-268.

Bryman, A., 2006. Integrating quantitative and qualitative research: how is it done?. Qualitative research 6(1), 97-113.

Carver, S., 2003. The future of participatory approaches using geographic information: Developing a research agenda for the $21^{\text {st }}$ century. Urisa Journal 15(1), 61-71.

Chambers, R., 2006. Participatory mapping and geographic information systems: Whose map? Who is empowered and who disempowered? Who gains and who loses? The Electronic Journal of Information Systems in Developing Countries 25(1), 1-11.

Das, S.K., Tripathi, H., 2011. Social change in gangetic delta of India: a participatory rural appraisal. International Journal of Bio-resource and Stress Management 2(2), 73-178.

Das, S.K., Tripathi, H., 2012. Household in Sundarban delta of India: a participatory rural appraisal. International journal of Bio-resource and Stress Management 3(2), 222-227.

Dunn, C.E., 2007. Participatory GIS-a people's GIS? Progress in human geography 31(5), 616-637.

Gautam, A.P., Webb, E.L., Eiumnoh, A., 2002. GIS assessment of land use/land cover changes associated with community forestry implementation in the middle hills of Nepal. Mountain Research and Development 22(1), 63-69.

Haklay, M., Singleton, A., Parker, C., 2008. Web mapping 2.0: The neogeography of the Geo Web. Geography Compass 2(6), 2011-2039.

Hassan, R., Nhemachena, C., 2008. Determinants of African farmers' strategies for adapting to climate change: Multinomial choice analysis. African Journal of Agricultural and Resource Economics 2(1), 83-104.

Islam, M.S., Rahman, S.M.A., Huq, S.M.S., 2016. Promoting self-employment in rural area through local government in Bangladesh: towards an encompassing approach for poverty mitigation. European Journal of Business and Social Sciences 5(03), 79-98.

Kalibo, H.W., Medley, K.E., 2007. Participatory resource mapping for adaptive collaborative management at $\mathrm{Mt}$. Kasigau, Kenya. Landscape and Urban Planning 82(3), 145-158.

King, B.H., 2002. Towards a participatory GIS: evaluating case studies of participatory rural appraisal and GIS in the developing world.Cartography and geographic information science 29(1), 43-52.

Koralagama, D., Wijeratne, M., De Silva, W., 2007. Emergence of participatory rural appraisal (PRA) technique as a strategy towards sustainable development: a Sri Lankan experience. Journal of Agriculture and Rural Development in the Tropics and Subtropics (JARTS)108(2), 149-160.

McCall, M.K., Dunn, C.E., 2012. Geo-information tools for participatory spatial planning: Fulfilling the criteria for 'good' governance? Geoforum 43(1), 81-94.

McCall, M.K., Minang, P.A., 2005. Assessing participatory GIS for community-based natural resource management: claiming community forests in Cameroon. The Geographical Journal 171(4), 340-356.

Pandian, S.L.E., Yarrakula, K., Chaudhury, P., 2018. GIS-Based Decision Support System for Village Level: A Case Study in Andhra Pradesh. In GIS Applications in the Tourism and Hospitality Industry. IGI Global, 275-295

Ramirez-Gomez, S.O., Torres-Vitolas, C.A., Schreckenberg, K., Honzak, M., Cruz-Garcia, G.S., Willcock, S., Palacios, E., Perez-Minana, E., Verweij, P.A., Poppy, G.M., 2015. Analysis of ecosystem services provision in the Colombian Amazon using participatory research and mapping techniques. Ecosystem Services 13, 93-107.

Rasul, G., Thapa, G.B., 2004. Sustainability of ecological and conventional agricultural systems in Bangladesh: an assessment based on environmental, economic and social perspectives. Agricultural systems 79(3), 327-351.

Reed, M.S., 2008. Stakeholder participation for environmental management: a literature review. Biological conservation 141(10), 2417-2431.

Ricaurte, L.F., Wantzen, K.M., Agudelo, E., Betancourt, B., Jokela, J., 2014. Participatory rural appraisal of ecosystem services of wetlands in the Amazonian Piedmont of Colombia: elements for a sustainable management concept. Wetlands ecology and management 22(4), 343-361.

Sieber, R., 2006. Public participation geographic information systems: A literature review and framework. Annals of the association of American Geographers 96(3), 491-507.

Tripathi, N., Bhattarya, S., 2004. Integrating indigenous knowledge and GIS for participatory natural resource management: state of the practice. The Electronic Journal Of Information Systems in Developing Countries 17(1), 1-13.

Zhang, H., Xu, M., Shi, X., Li, Z., Huang, Q., Wang, X., 2010. Rice yield, potassium uptake and apparent balance under long-term fertilization in rice-based cropping systems in southern China. Nutrient Cycling in Agroecosystems 88(3), 341-349. 